\title{
Incremento en la proteína no degradable en rumen de vacas lecheras: 1. Efectos sobre la producción y composición de leche y utilización de nutrientes ${ }^{\#}$
}

\author{
Increasing of rumen undegradable protein in dairy cows. 1. Effects on milk production, \\ milk composition and nutrients utilization
}

D Ibarra ${ }^{1}$, L Latrille ${ }^{2}$

Facultad de Ciencias Agrarias, Instituto de Producción Animal, Universidad Austral de Chile. Casilla 567, Valdivia, Chile.

${ }^{1}$ Dirección actual: Departamento de Reproducción Animal, Facultad de Veterinaria, Universidad de la República, Lasplaces 1550, Montevideo, Uruguay. E-mail: dibarra@adinet.com.uy

2 Instituto de Producción Animal, Universidad Austral de Chile, Valdivia, Chile.

\begin{abstract}
SUMMARY
One of the most limiting and expensive nutrients for high producing dairy cows is crude protein (CP) and particularly RUP. Winter diets for dairy cattle in Southern Chile are based mainly on silages. The aim of the study was to analize the effects of the level of RUP in diets which include high levels of pasture silage and alfalfa haylage. High silage diets were fed to twelve multiparous Holstein cows in two trials to establish the effects of RUP supplementation on milk production, composition and efficiency of production. A complete Latin square design was used. Diets identified as A1 and B1 included (on a DM basis) $45 \%$ grass silage (GS) and 20\% alfalfa haylage (AH) while diets A2 and B2 had $38 \%$ GS and 27\% AH. The B diets were adjusted considering RUP (NRC, 1989) with fishmeal in the concentrate while the A diets considered only $\mathrm{CP}$ requirements, accepting up to a $20 \%$ RUP deficiency, and included soybean meal. DM, NEL and CP intakes were similar between treatments Daily milk and protein yield and concentration were higher with fish meal supplemented diets $(\mathrm{P}<0.05)$ but fat concentration was lower $(\mathrm{P}<0.05)$. MUN was similar between treatments and all values were lower than $19 \mathrm{mg} \mathrm{dl}^{-1}$. Apparent efficiency of utilisation of DM and NEL for milk production, FCM and milk protein were higher $(\mathrm{P}<0.05)$ with fish meal diets. There was no interaction between alfalfa haylage and RUP level, except for milk protein level. Therefore providing RUP with fishmeal resulted in a higher milk and protein production and improved the efficiency of nutrient utilization, and this effect was not related to alfalfa haylage level.
\end{abstract}

Palabras clave: ensilaje praderas, ensilaje alfalfa, harina pescado.

Key words: grass silage, alfalfa haylage, fish meal .

\section{INTRODUCCION}

El ensilaje de praderas, y en menor medida el henilaje de alfalfa, son las principales fuentes de alimentación durante el invierno para las vacas lecheras en la región sur de Chile. Ambos alimentos se caracterizan por su relativamente alto contenido de PC y porque su degradabilidad en rumen es alta. Esto tiene consecuencias nutricionales. Dhiman y Satter (1993) demostraron que con dietas basadas en henilaje de alfalfa, el nutriente que limita la producción es la proteína no degradable en el rumen (PNDR). Es por ello que existe mucho interés en suplementar dietas basadas en estos forrajes con su-

Aceptado: 28.02.2006

\# Financiado por Proyecto FONDECYT 1961045 plementos que provean PNDR, como las harinas de soya tratadas con formaldehído o proteínas de origen animal como la harina de pescado. Sin embargo, debe tenerse cuidado y evitar una suplementación excesiva con nitrógeno, ya que los excedentes son excretados en fecas y particularmente en orina, lo que contribuye a la contaminación del medio ambiente (Castillo y col 2001).

Por otro lado, tanto las industrias lácteas como el mercado han establecido nuevos sistemas de pago para la leche, basados en composición y especialmente en el contenido de proteína. Esto ha estimulado la investigación sobre las causas que determinan el contenido proteico de la leche (De Peters y Cant 1992). En este sentido, la cantidad, composición y degradabilidad de la proteína son importantes. Sin embargo, algunos ensayos comparando diferentes formas de proveer los requerimientos de proteína en vacas lecheras han tenido resul- 
tados contradictorios sobre el contenido de proteína de la leche (Grummer y col 1996, Polan y col 1997).

Considerando lo anterior, la hipótesis de este estudio fue que, en dietas con altos niveles de forraje proveniente de ensilajes de praderas y henilaje de alfalfa, concentrados que contienen una fuente de proteína que aporta una cantidad adecuada de PNDR tienen efectos positivos sobre la producción y composición de la leche y sobre la eficiencia de utilización de los nutrientes al compararse con concentrados que aportan menos PNDR.

\section{MATERIALES Y METODOS}

Este trabajo se realizó en la Estación Experimental Vista Alegre de la Universidad Austral de Chile, ubicada en el paralelo $39^{\circ} 47^{\prime}$ lat. sur y $73^{\circ} 13^{\prime}$ long. oeste, en Valdivia, Chile. El primer mes se consideró como período preexperimental. El experimento evaluó el ajuste en requerimientos de PNDR, mediante la inclusión de harina de pescado, sobre la producción y composición de leche y la eficiencia de utilización de los nutrientes.

\section{PRODUCCION, COMPOSICION Y EFICIENCIA} DE PRODUCCION DE LECHE

Diseño experimental. Doce vacas Holstein-Friesian, multíparas, entre 3 y 5 meses de lactancia, fueron agrupadas en 3 cuadrados latinos con cambio sobre diseño (Gill, 1981) con 4 períodos y 4 dietas. Cada período consistió en una primera semana de adaptación a la respectiva dieta y una segunda semana donde se colectaba la información. Los animales estaban estabulados y contaban con comederos y bebederos individuales. La ración se ofrecía en cantidades que consideraban hasta un $10 \%$ de rechazo. Cuando los animales consumían la totalidad de lo ofrecido, al día siguiente la ración se incrementaba en $5 \%$.

Evaluación de las dietas. Se determinó materia seca (MS), proteína cruda (PC), fibra detergente neutro (FDN), fibra detergente ácida (FDA), nitrógeno insoluble en la fibra detergente neutro (FDNIN), nitrógeno insoluble en la fibra detergente ácida (FDAIN), Ca y P. Todas las dietas estudiadas tuvieron una relación ensilajes: concentrado de 65:35\% (BMS). Las dietas identificadas como A1 y B1 incluían un $45 \%$ de ensilaje de pradera y un $20 \%$ de henilaje de alfalfa. Las identificadas como A2 y B2 incluyeron un 38\% de ensilaje de pradera permanente y un $27 \%$ de henilaje de alfalfa. La diferencia entre las dietas "A" (A1 y A2) y las dietas "B" (B1 y B2) se obtuvo formulando las dietas "A" considerando, en el caso del N, sólo las recomendaciones de PC (NRC 1989), pero aceptando un déficit de hasta $20 \%$ en PNDR, mientras que las dietas "B" satisfacían los requerimientos de PC y de PNDR. Para ello se utilizaron valores de PNDR tabu- lados, empleando una tabla de composición de alimentos generada localmente (Anrique y col 1995).

Alimentos. Tanto el concentrado como el ensilaje ofrecidos, al igual que el rechazo, eran pesados diariamente. En el laboratorio se determinó MS del ensilaje por secado en horno a $105^{\circ} \mathrm{C}$. La proteína cruda (PC) se determinó con la técnica de Kjeldhal de medición indirecta basada en una digestión ácida siendo el factor de conversión de $\mathrm{N}$ a proteína de 6.25 (AOAC 1996). La EM se estimó a partir de una regresión (Garrido y Mann 1981) del valor D (materia orgánica digestible/MS x 100), determinado in vitro, según el método de dos etapas de fluido ruminal y $\mathrm{HCl}$ pepsina (Tilley y Terry 1963). La determinación de FDN y FDA se realizó de acuerdo a Van Soest y col (1991), mientras que la de FDAIN y FDNIN se realizó de acuerdo a AOAC 1996. Del rechazo se tomaba una muestra diaria y se hacía un pool semanal en el que se determinaba $\mathrm{MS}$ en horno a $105^{\circ} \mathrm{C}$ y $\mathrm{PC}$ según Kjeldahl (AOAC 1996) para cuantificar de manera exacta el consumo. Los valores de degradabilidad en rumen de la proteína fueron tomados de tabla (Anrique y col 1995).

Leche. Los volúmenes de leche diarios se midieron diariamente en cada ordeña (6.00 y 16.30 horas) tomándose muestras de cada animal para la determinación de grasa, proteína y urea. Estas muestras se preservaron con dicromato de potasio y fueron refrigeradas a $4^{\circ} \mathrm{C}$ hasta ser enviadas al laboratorio. Tanto la proteína verdadera como la grasa fueron determinadas con un aparato Milko-Scan sistema 4000, serie 300 (Fosselectric, Dinamarca). La urea fue determinada por el método ureasaBerthelot modificado (urea color Boehringer Mannheim).

ANALISIS ESTADISTICO. Los datos se analizaron con el paquete estadístico SAS (SAS 1995), empleando el procedimiento GLM, de acuerdo al siguiente modelo:

$$
Y_{i j k l}=\mu+B_{i}+P_{j}+T_{k}+C_{1}+E_{i j k l}
$$

Siendo:

$\mathrm{Y}_{\mathrm{ijkl}}=$ variable dependiente

$\mathrm{m}=$ media de $\mathrm{Y}$, considerada como la sumatoria en el período de 2 semanas

$\mathrm{B}_{\mathrm{i}}=$ efecto del bloque $(\mathrm{i}=1,2,3,4)$

$P_{j}=$ efecto del período $(j=1,2,3,4)$

$\mathrm{T}_{\mathrm{k}}=$ efecto del tratamiento $(\mathrm{k}=1,2,3,4)$

$\mathrm{C}_{1}=$ efecto del cuadrado latino $(\mathrm{l}=1,2,3)$

$\mathrm{E}_{\mathrm{ijkl}}=$ error residual

Las variables, cuyo análisis de varianza dio como resultado diferencias significativas $(\mathrm{P}<0,05)$, fueron sometidas a una prueba de comparación de medias, utilizándose la prueba de contrastes ortogonales (95\%). Se analizó también la interacción entre el nivel de PNDR y de henilaje de alfalfa. 


\section{RESULTADOS}

COMPOSICION DE LAS DIETAS Y CONSUMO. El componente más importante (en base MS) de las dietas fue el ensilaje de praderas, seguido del henilaje de alfalfa. En el concentrado los granos de maíz y de avena y el gluten de maíz fueron ingredientes importantes. La diferencia principal entre las dietas denominadas A y B fue la presencia o no de harina de pescado y de harina de soya (cuadro 1). La harina de pescado utilizada, contenía (en base MS) $10,75 \%$ de extracto etéreo. Considerando la composición de nutrientes, la principal diferencia entre las dietas A y $\mathrm{B}$ fue el nivel de PNDR, ya que los contenidos de PC y energía fueron muy similares. Existieron diferencias significativas $(\mathrm{P}<0,05)$ en el consumo de PNDR entre dietas A y B, aunque no existieron diferencias entre las dietas denominadas 1 ni entre las 2, i.e. que tenían iguales relaciones entre ensilaje de pradera y henilaje de alfalfa. Los consumos totales de MS, PC y ENL no fueron diferentes $(\mathrm{P}>0,05)$ (cuadro 2). No existieron interacciones entre el nivel de PNDR y el nivel de inclusión de henilaje de alfalfa

PRODUCCION Y COMPOSICION DE LECHE. Existieron diferencias significativas $(\mathrm{P}<0,01)$ en producción de leche entre dietas con diferentes niveles de PNDR (dietas A vs. B),

Cuadro 1. Composición de ingredientes y nutrientes de las dietas utilizadas (\% base MS). Ingredients and nutrient composition of the diets (\% DM basis).

\begin{tabular}{|c|c|c|c|c|c|c|}
\hline Ingrediente & A 1 & B 1 & A 2 & B 2 & $\begin{array}{c}\text { PP } \\
\text { ensilaje }\end{array}$ & $\underset{\text { henilaje }}{\mathrm{AA}}$ \\
\hline Ensilaje de pradera & 45 & 45 & 38 & 38 & & \\
\hline Henilaje de alfalfa & 20 & 20 & 27 & 27 & & \\
\hline Maíz & 14,97 & 15,04 & 15,28 & 15,71 & & \\
\hline Avena & 7,02 & 7,65 & 6,56 & 6,22 & & \\
\hline Triticale & - & - & - & 2,68 & & \\
\hline Harina de pescado & - & 4,46 & - & 4,67 & & \\
\hline Afrecho de soja & 5,32 & - & 5,08 & - & & \\
\hline Gluten de maíz & 7,84 & 7,01 & 7,18 & 4,93 & & \\
\hline Mezcla mineral & 0,85 & 0,84 & 0,90 & 0,79 & & \\
\hline \multicolumn{7}{|l|}{ Nutrientes } \\
\hline$\overline{\mathrm{MS}}$ & 45,95 & 46,10 & 47,02 & 47,33 & 17,1 & 40,0 \\
\hline $\mathrm{PC}^{\mathrm{z}}$ & 15,29 & 15,60 & 15,77 & 16,16 & 12,1 & 19,5 \\
\hline PNDR y & 25,28 & 31,10 & 24,92 & 29,63 & & \\
\hline Proteína soluble & & & & & 5,55 & 10,35 \\
\hline ENL $^{x}$ & 1,64 & 1,63 & 1,63 & 1,61 & 1,62 & 1,43 \\
\hline $\mathrm{FDA}^{\mathrm{z}}$ & 28,87 & 22,12 & 28,88 & 28,23 & 40,2 & 39,1 \\
\hline FDAIN $^{z}$ & 1,07 & 1,06 & 1,07 & 0,98 & 0,90 & 0,71 \\
\hline $\mathrm{FDN}^{\mathrm{z}}$ & 44,11 & 45,11 & 43,49 & 43,08 & 61,8 & 45,4 \\
\hline FDNIN $^{z}$ & 0,97 & 1,06 & 1,05 & 1,21 & 1,00 & 0,93 \\
\hline Cenizas & & & & & 8,25 & 8,68 \\
\hline $\mathrm{Ca}^{2}$ & 0,68 & 0,98 & 0,63 & 0,90 & & \\
\hline $\mathrm{P}^{\mathrm{z}}$ & 0,41 & 0,56 & 0,42 & 0,47 & & \\
\hline
\end{tabular}

(z:\% de la MS; ${ }^{\mathrm{y}}: \%$ de PC; ${ }^{\mathrm{x}}$ : Mcal kg-1 MS).

Cuadro 2. Efecto del incremento de la PNDR mediante harina de pescado sobre consumo en vacas lecheras con dietas basadas en ensilaje .

Effects of increasing RUP through fish meal on intake of dairy cows on silage based diets .

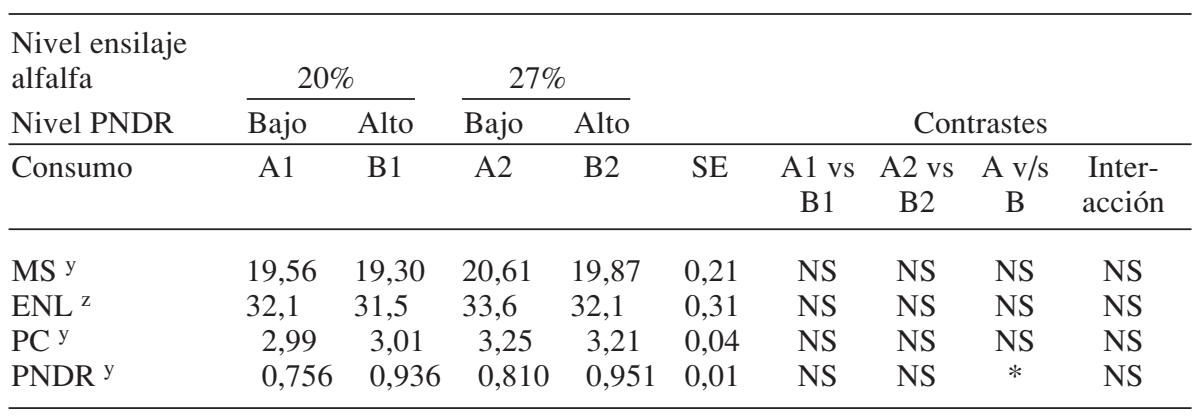

(': $\mathrm{kg} ;{ }^{\mathrm{z}}$ : Mcal).

*: $\mathrm{P}<0,05$; NS: $\mathrm{P}>0,05$ 
diferencias que se explican por los mayores niveles de producción obtenidos con las dietas B1 vs A1 $(\mathrm{P}<0,01)$ (cuadro 3). Los análisis de contrastes ortogonales muestran que las dietas $\mathrm{B}$ generaron un mayor contenido y producción de proteína láctea $(\mathrm{P}<0,01)$. Para el contenido de proteína, este efecto fue significativo solamente en la dieta con mayor nivel de henilaje de alfalfa (dieta B2). Por otro lado, aunque las producciones de grasa no fueron diferentes, los contenidos de grasa en la leche fueron significativamente mayores en las dietas suplementadas con harina de soya (dietas $\mathrm{A})(\mathrm{P}<0,01)$, independientemente de la combinación de forraje utilizada. No existieron diferencias entre los tratamientos $(\mathrm{P}>0,05)$ en el contenido de $\mathrm{N}$ ureico en leche aunque los mismos estuvieron por debajo de los valores considerados críticos (19 $\left.\mathrm{mg} \mathrm{dl}^{-1}\right)$. No existieron interacciones entre el nivel de henilaje de alfalfa y de PNDR, excepto para el contenido de proteína láctea expresado en porcentaje.

EFICIENCIA DE LA PRODUCCION DE LECHE Y DE PROTEINA. Considerando la conveniencia de incrementar la eficiencia de producción de leche y, particularmente, de los componentes de la leche, se analizaron los efectos de las diferentes formas de suplementar con concentrados sobre la eficiencia de producción de leche y de proteína (cuadro 4). Se observó que las dietas formuladas para aportar más PNDR (dietas B) generaron mejores eficiencias de utilización de la MS y de la ENL consumi-

Cuadro 3. Efecto del incremento de la PNDR mediante harina de pescado sobre producción y composición de leche en vacas lecheras con dietas basadas en ensilaje.

Effects of increasing RUP with fish meal on intake and milk production and composition from dairy cows fed silage based diets.

\begin{tabular}{|c|c|c|c|c|c|c|c|c|c|}
\hline Nivel PNDR & Bajo & Alto & Bajo & Alto & & \multicolumn{4}{|c|}{ Contrastes } \\
\hline Variable & A1 & B1 & $\mathrm{A} 2$ & B2 & $\overline{\mathrm{SE}}$ & $\begin{array}{c}\text { A1 vs } \\
\text { B1 }\end{array}$ & $\begin{array}{c}\text { A2 vs } \\
\text { B2 }\end{array}$ & $\begin{array}{c}\text { A vs } \\
\text { B }\end{array}$ & $\begin{array}{l}\text { Inter- } \\
\text { acción }\end{array}$ \\
\hline $\begin{array}{l}\text { Producción } \\
\text { de leche }\end{array}$ & 24,2 & 25,7 & 25,5 & 25,7 & 0,24 & $* *$ & NS & $* *$ & NS \\
\hline $\mathrm{LCG} 4 \% \mathrm{v}$ & 24,4 & 25,4 & 25,7 & 24,9 & 0,28 & NS & NS & NS & NS \\
\hline Proteína $\mathrm{x}$ & 3,07 & 3,10 & 3,03 & 3,14 & 0,016 & NS & $* *$ & $* *$ & * \\
\hline $\begin{array}{l}\text { Producción } \\
\text { de proteína }^{\mathrm{y}}\end{array}$ & 0,74 & 0,80 & 0,77 & 0,81 & 0,008 & $* *$ & $* *$ & $* *$ & NS \\
\hline Grasa $x$ & 4,08 & 3,91 & 4,04 & 3,79 & 0,041 & $*$ & $*$ & $* *$ & NS \\
\hline $\begin{array}{l}\text { Producción } \\
\text { de grasa } \\
\text { y ureico }\end{array}$ & 0,98 & 1,01 & 1,03 & 0,97 & 0,013 & NS & NS & NS & NS \\
\hline en leche $\mathrm{z}$ & 17,50 & 17,14 & 18,22 & 18,33 & 0,200 & NS & NS & NS & NS \\
\hline
\end{tabular}

(": lts día ${ }^{-1} ;{ }^{\mathrm{x}}: \%$; $\left.{ }^{\mathrm{y}}: \mathrm{kg} \mathrm{día}^{-1} ;{ }^{\mathrm{z}}: \mathrm{mg} \mathrm{dl}^{-1}\right)$.

$* *: \mathrm{P}<0,01 ; * \mathrm{P}<0,05$; NS: $\mathrm{P}>0,05$.

Cuadro 4. Efecto del incremento de la PNDR mediante harina de pescado sobre la eficiencia de utilización de los nutrientes consumidos para la producción de leche, LCG y proteína en vacas lecheras con dietas basadas en ensilaje.

Effects of increasing RUP with fish meal on efficiency of utilization of nutrients intake for milk, FCM and protein production in dairy cows fed silage based diets.

\begin{tabular}{|c|c|c|c|c|c|c|c|c|c|}
\hline Relación & A1 & B1 & A2 & B1 & SE & $\begin{array}{c}\text { A1 vs } \\
\text { B1 }\end{array}$ & $\begin{array}{c}\mathrm{A} 2 \mathrm{vs} \\
\mathrm{B} 2\end{array}$ & $\begin{array}{c}\text { A vs } \\
\text { B }\end{array}$ & $\begin{array}{l}\text { Inter- } \\
\text { acción }\end{array}$ \\
\hline Prod/MS v & 1,25 & 1,34 & 1,24 & 1,30 & 0,012 & $* *$ & * & $* *$ & NS \\
\hline Prod/ENL x & 0,758 & 0,820 & 0,764 & 0,806 & 0,007 & $* *$ & * & $* *$ & NS \\
\hline Prod/PC v & 8,31 & 8,62 & 7,92 & 8,15 & 0,11 & NS & NS & NS & NS \\
\hline $\mathrm{LCG} / \mathrm{MS}^{\mathrm{v}}$ & 1,25 & 1,32 & 1,24 & 1,26 & 0,015 & $* *$ & NS & $*$ & NS \\
\hline LCG/ENL ${ }^{x}$ & 0,762 & 0,811 & 0,768 & 0,773 & 0,009 & $* *$ & NS & $* *$ & NS \\
\hline $\mathrm{LCG} / \mathrm{PC}^{\mathrm{v}}$ & 8,27 & 8,61 & 7,80 & 8,08 & 0,146 & NS & * & NS & NS \\
\hline Prot/MS y & 0,038 & 0,041 & 0,038 & 0,041 & 0,0004 & $* *$ & $* *$ & $* *$ & NS \\
\hline Prot/ENL z & 0,023 & 0,025 & 0,023 & 0,025 & 0,0002 & $* *$ & $* *$ & $* *$ & NS \\
\hline Prot/PC y & 0,254 & 0,267 & 0,239 & 0,256 & 0,0035 & NS & NS & NS & NS \\
\hline
\end{tabular}

Prod: producción diaria de leche; Prot: producción diaria de proteína láctea.

( ${ }^{\mathrm{v}}:$ lt kg. ${ }^{-1}$; ${ }^{\mathrm{x}}$ : lt $\mathrm{Mcal}^{-1} ;{ }^{\mathrm{y}}: \mathrm{kg} \mathrm{kg}^{-1}$; ${ }^{\mathrm{z}}$ : $\mathrm{kg} \mathrm{Mcal}^{-1}$ ).

$* *: \mathrm{P}<0,01 ; *: \mathrm{P}<0,05 ; \mathrm{NS}: \mathrm{P}>0,05$ 
das para la producción de leche (sin corregir), de leche corregida al 4\% de grasa (LCG), producción de grasa y de proteína. Estas diferencias en producción de leche y de leche corregida al $4 \%$ de grasa fueron más importantes en las dietas que contenían mayores niveles de ensilaje de pradera (dietas 1). No existieron diferencias entre las dietas respecto a la utilización de la PC ( $\mathrm{P}>0.05)$. Tampoco existieron interacciones entre el nivel de PNDR y de henilaje de alfalfa.

\section{DISCUSION}

CONSUMO, PRODUCCION Y COMPOSICION DE LA LECHE. Las diferencias significativas $(\mathrm{P}<0.05)$ en el consumo estimado de PNDR entre las dietas A y B (cuadro 2) se relacionan a los mayores contenidos de harina de pescado en las dietas B, ya que no existieron diferencias en el consumo de MS ni de PC. Los análisis de contrastes ortogonales (cuadro 3) indicaron que las dietas suplementadas con harina de pescado (dietas B) produjeron más leche. La no existencia de diferencias en leche corregida al $4 \%$ de grasa se explica por la inclusión de harina de pescado que contenía $10,75 \%$ de aceite, ya que se ha demostrado que altos niveles de grasa en la ración deprimen el contenido de grasa de la leche (Hussein y Jordan 1991, Spain y col 1995).

La mayor producción de leche de dietas con mayor nivel de PNDR (B versus A) puede tener diferentes explicaciones. Varios autores (Wohlt y col 1991, Carrol y col 1994, O'Mara y col 1998, Wright y col 1998) encontraron que, al suplementar con harina de pescado como fuente de PNDR, se incrementa el perfil aminoacídico en el duodeno, particularmente de lisina y metionina, generalmente considerados como limitantes. Las dietas B tuvieron un efecto claro en la proteína de la leche: produjeron tanto una mayor concentración como un mayor rendimiento de proteína $(\mathrm{P}<0,05)$ (cuadro 3). Esta respuesta en producción de proteína puede ser explicada por un mayor consumo de PNDR; en este trabajo se encontró una correlación significativa $(\mathrm{r}=0,71)$ entre consumo de PNDR y proteína de la leche en las dietas B, es decir, ajustadas por PNDR. Esta respuesta fue mejor en las vacas que recibieron una mayor proporción de henilaje de alfalfa (dietas 2) y que fueron suplementadas con concentrado conteniendo harina de pescado, ya que la interacción entre nivel de PNDR y de henilaje de alfalfa fue significativa $(\mathrm{P}<0,05)$. Esto podría ser el resultado de un mejor flujo de aminoácidos esenciales al intestino (Santos y col 1998).

Los efectos del consumo de energía, PC y PNDR sobre la composición de la leche han sido extensamente investigados. Nuestros resultados coinciden con Emery (1978), quien describe que el porcentaje de PC de la dieta se relacionó al contenido de proteína de la leche $(\mathrm{r}=0,59)$; en nuestro ensayo esta correlación fue menor $(\mathrm{r}=0,37)$ pero significativa $(\mathrm{P}<0,05)$. Existió una alta co- rrelación entre consumo de ENL y producción de proteína $(r=0,68)$, valor mayor que el descrito por Emery (1978) $(\mathrm{r}=0,42)$ aunque menor que el valor encontrado por De Peters y Cant $(1992)(\mathrm{r}=0,89)$.

Roseler y col (1993) relacionaron diferentes factores que afectan la producción de proteína de la leche, los cuales fueron descritos a través de la siguiente ecuación de regresión múltiple:

Producción de proteína de leche $(\mathrm{kg} /$ día $)=-0,041+$ $0,023^{*}$ producción de leche $+0,022 *$ Consumo de PNDR $+0,006 *$ consumo de ENl $\left(r^{2}=0,86\right)$.

En nuestro trabajo, estos factores se relacionan de manera similar (datos no presentados). Esto implica que producción de leche, y consumo de PNDR y ENL contribuyen a explicar las producciones diarias de proteína de la leche.

Las dietas con mayores niveles de PNDR probablemente generaron un mejor patrón de aminoácidos a nivel intestinal, debido a la inclusión de una fuente balanceada de PNDR (harina de pescado). El uso de este suplemento incrementó la producción de leche y su contenido de proteína, con una reducción en el contenido de grasa. Esto último puede ser explicado por un efecto negativo del aceite presente en la harina de pescado sobre la producción de ácidos grasos volátiles (AGV) microbianos (Hussein y Jordan 1991) o por una alteración en el metabolismo lipídico postabsorción (Spain y col 1995). Un efecto similar puede haber ocurrido en nuestro trabajo y ha sido descrito por otros (Grummer y col 1996, O'Mara y col 1998). La PNDR aportada por la harina de pescado puede haber mejorado el patrón de aminoácidos, aunque el flujo total de estos nutrientes ha mostrado sólo un ligero incremento en otros experimentos (De Peters y Cant 1992, Clark y col 1992), aunque este efecto podría ser mayor en dietas basadas en henilaje de alfalfa (Dhiman y Satter 1993)

La inexistencia de una interacción entre la cantidad de PNDR y de ensilajes discrepa con los resultados de otros autores, que describen un efecto importante de la fuente de ensilaje sobre la producción de leche, observándose una mejor producción con dietas basadas en ensilaje de alfalfa versus ensilajes de ballica inglesa (Broderick y col 2002) o de trébol rosado (Broderick y col 2001), lo que se explica en parte por los mayores consumos de las dietas con ensilaje de alfalfa. En nuestros resultados, si bien los consumos son mayores en dietas con mayores niveles de alfalfa (dietas 2), este mayor consumo no es significativo, lo que posiblemente se explica por la escasa diferencia en el nivel de alfalfa entre las 2 dietas (i.e. 20 vs. $27 \%$, base MS) .

En relación al contenido de $\mathrm{N}$ ureico en leche (cuadro 3), este parámetro está siendo considerado cada vez con mayor importancia como un indicador de desbalances nutricionales así como de potenciales problemas reproductivos. Esto último ha sido atribuido a un incremento del amoníaco en rumen y en sangre que podría 
reducir la secreción de progesterona, alterar el pH uterino o incrementar el balance energético negativo (Butler 2000). Los valores encontrados en este ensayo no fueron diferentes entre tratamientos y todos los valores fueron menores a los considerados críticos $(19 \mathrm{mg} / \mathrm{dl})$ por investigadores norteamericanos (Baker y col 1995) como indicadores de desbalances entre la tasa de degradación ruminal de carbohidratos y de proteínas y como indicador de posibles problemas reproductivos. Algunos trabajos han observado una relación entre consumo de PNDR y $\mathrm{N}$ ureico en leche, lo que se ha atribuido a una utilización de aminoácidos, sea endógenos o provenientes de la dieta como sustratos para neoglucogénesis (Roseler y col 1993, Polan y col 1997, Rodríguez y col 1997). En este trabajo, los animales alimentados con las dietas con mayores niveles de PNDR no mostraron un incremento en $\mathrm{N}$ ureico, indicando probablemente que el total de proteína ofrecida en la dieta no excedía los requerimientos

EFICIENCIA DE LA PRODUCCION DE LECHE Y DE PROTEINA LACTEA. Las dietas B (con mayores aportes de PNDR) permitieron una mayor eficiencia de utilización de la MS y de la ENL para producción de leche, LCG y proteína (cuadro 4). Estas eficiencias son menores que las descritas por Broderick y col (2002), quienes obtuvieron 1,65 a 2,15 lts de leche por $\mathrm{kg}$ de MS consumida, aunque en su caso las dietas tenían mayores niveles de proteína y la dieta era de mayor calidad, a juzgar por su contenido de FDA. No existieron diferencias en la utilización de la PC, lo que discrepa con Baker y col (1995), aunque en su caso los desbalances en los aportes de proteína entre las dietas fueron mayores que en nuestro experimento. Broderick y col (2002) obtuvieron mejores eficiencias de utilización del $\mathrm{N}$ consumido, con valores entre 378 y $295 \mathrm{~g} / \mathrm{kg}$ de proteína consumida, diferencias que también pueden explicarse a partir de la mayor digestibilidad de la dieta. La mayor eficiencia de utilización de la MS y de la energía consumida observada en nuestro ensayo puede ser explicada por un ajuste más preciso de los aportes de nutrientes en las dietas con mayores niveles de PNDR, aportada por la harina de pescado

\section{RESUMEN}

Uno de los nutrientes más importantes en la dieta de vacas lecheras de alta producción es la proteína, y, en particular, la PNDR. Las dietas invernales de las vacas lecheras en el sur de Chile se basan en ensilajes. Por ello, parece interesante analizar el efecto de ajustar el contenido de PNDR en dietas con diferentes aportes de ensilajes de pradera y henilaje de alfalfa. Dietas con altos contenidos de ensilaje fueron suministradas a doce vacas Holstein multíparas para establecer el efecto de la suplementación con PNDR sobre la producción y composición de la leche y sobre la utilización de nutrientes. Se utilizó un modelo de cuadrados latinos completos. Las dietas designadas A1 y B1 incluían (base MS) 45\% de ensilaje de pradera (EP) y
$20 \%$ de henilaje de alfalfa (HA), mientras que las dietas A2 y B2 tenían un $38 \%$ de EP y un $27 \%$ de HA. Las dietas B fueron ajustadas considerando las recomendaciones de PNDR (NRC 1989) con harina de pescado en el concentrado; las dietas A consideraron sólo satisfacer los requerimientos de PC, aceptando un déficit de hasta $20 \%$ en la PNDR e incluían afrecho de soya. Los consumos de MS, ENL y PC fueron similares entre tratamientos. La producción de leche y de proteína, así como el contenido de proteína láctea, fueron mayores en las dietas suplementadas con harina de pescado (Dietas B) $(\mathrm{P}<0,05)$, pero el contenido de grasa fue menor $(\mathrm{P}<0,05)$. El $\mathrm{N}$ ureico en leche fue similar entre tratamientos, pero todos los valores estuvieron por debajo de los valores considerados críticos $\left(19 \mathrm{mg} \mathrm{dl}^{-1}\right)$. La eficiencia de utilización de la MS y de la ENL para la producción de leche, tal cual o corregida (4\% MG) y de proteína láctea fueron mayores $(\mathrm{P}<0,05)$ con las dietas $\mathrm{B}$. No existió interacción entre nivel de PNDR y henilaje de alfalfa, excepto para contenido de proteína de la leche. Ajustar PNDR de la dieta con harina de pescado generó una mayor producción de leche y de proteína e incrementó la eficiencia de utilización de la ENL y de PC y este efecto no se relacionó al nivel de henilaje de la dieta.

\section{AGRADECIMIENTOS}

A los profesores R. Smith y F. Mujica en el diseño experimental y análisis estadístico; a los Drs. S. Tamminga y P. Chilibroste por la revisión crítica del artículo.

\section{REFERENCIAS}

Anrique R, X Valderrama, R Fuchslocher. 1995. Tabla de composición de alimentos para el ganado de la zona sur. Ed. Fundación Fondo de Investigación Agropecuario. Ministerio de Agricultura.

Association of official analytical chemists. 1996. Official methods of analysis. $16^{\text {th }}$ ed. AOAC, Arlington, VA.

Baker LD, JD Fergusson, W Chalupa. 1995. Responses in urea and true protein of milk to different protein feeding schemes for dairy cows. J Dairy Sci 78, 2424-2434.

Broderick GA, RP Walgenbach, S Maignan. 2001. Production of lactating dairy cows fed alfalfa or red clover silage at equal dry matter or crude protein contents in the diet. J Dairy Sci 84: 1728-1737

Broderick G, R Koegel, R Walgenbach, T Kraus. 2002. Ryegrass or alfalfa silage as the dietary forage for lactating dairy cows. J Dairy Sci 85, 1894-1901.

Butler WR 2000. Nutritional interactions with reproductive performance in dairy cattle. Anim Reprod Sci 60-61: 449-457.

Carrol D, F Hossain, M Keller. 1994. Effect of supplemental fish meal on the lactation and reproductive performance of dairy cows. J Dairy Sci 77, 3058-3072.

Castillo AR, E Kebreath, DE Beever, JH Barbi, JD Sutton, HC Kirby, J France. 2001. The effect of protein supplementation on nitrogen utilization in lactating dairy cows fed grass silage diets. J Anim Sci 79, 247-253.

Clark JH, TH. Klusmeyer, MR Cameron. 1992. Microbial protein synthesis and flows of nitrogen fractions to the duodenum of dairy cows. J Dairy Sci 75, 2304-2323.

De Peters EJ, JP Cant. 1992. Nutritional factors influencing the nitrogen composition of bovine milk: a review. J Dairy Sci 75, 2043-2070. 
Dhiman TR, LD Satter. 1993. Protein as the first limiting nutrient for lactating dairy cows fed high proportions of good quality alfalfa silage. J Dairy Sci 76, 1960-1968.

Emery R.1978. Feeding for increased milk protein. J Dairy Sci 61, 825-828.

Garrido O, E Mann. 1981. Composición química, digestibilidad y valor energético de una pradera permanente de pastoreo a través del año. Tesis Ing. Agr. Valdivia, Universidad Austral de Chile, Facultad de Ciencias Agrarias. Pp 63.

Gill JL. 1981. Design and analysis of experiments in the animal and medical sciences, vol 2. The Iowa University Press. Pp 473.

Grummer R, K Slark, S Bertics, M Luck, J Barmore. 1996. Soybeans versus animal sources of rumen-undegradable protein and fat for early lactation dairy cows. J Dairy Sci 79, 1809-1816.

Hussein HS, RM Jordan. 1991. Fish meal as a protein supplement in ruminants diets: a review. J Anim Sci 69, 2147-2156.

National Research Council. 1989. Nutrients requirements for dairy cattle. $6^{\text {th }}$ rev. ed. National Academy Press. Washington, DC.

O'Mara FP, J Murphy, M Rath. 1998. Effect of amount of dietary supplement and source of protein on milk production, ruminal fermentation, and nutrient flows in dairy cows. J Dairy Sci 81, 2430-2439.

Polan C, G Cozzi, P Berzaghi, I Andrighetto. 1997. A blend of animal and cereal protein or fish meal as partial replacement for soybean meal in the diets of lactating Holstein cows. $J$ Dairy Sci 80, 160-166.
Rodríguez L, C Stallings, J Herbein, ML Mcgilliard. 1997. Effect of degradability of dietary protein and fat on ruminal, blood, and milk components of Jersey and Holstein cows. J Dairy Sci 80, 353-363.

Roseler D, J Fergusson, C Sniffen, J Herrema. 1993. Dietary protein degradability effects on plasma and milk urea nitrogen and milk nonprotein nitrogen in Holstein cows. J Dairy Sci 76, 525-534.

Santos FA, JE Santos, C Theurer, JT Huber. 1998. Effects of rumen-undegradable protein on dairy cow performance: a 12 year literature review. J Dairy Sci 81, 3182-3213.

Sas User's Guide: Statistics. Version 1995. SAS Inst. Inc., Cary, $\mathrm{NC}$.

Spain JN, Polan, CE, BA Watkins 1995. Evaluating effects of fish meal on milk fat yield of dairy cows. J Dairy Sci 78, 1142-1153.

Tilley J, R Terry. 1963. A two stage technique for the in vitro digestion of forage crops. J British Grassland Soc 18, 104-111.

Van Soest PJ, J Robertson, B Lewis. 1991. Methods for dietary fiber, neutral detergent fiber, and nonstarch polysaccharides in relation to animal nutrition. J Dairy Sci 74, 3583-3595.

Wohlt JE, S Chmiel, P Zajac, L Baker, D Blethen, J Evans. 1991. Dry matter intake, milk yield and composition, and nitrogen use in Holstein cows fed soybean, fish, or corn gluten meals. J Dairy Sci 74, 1609-1622.

Wright T, S Moscadini, P Luimes, P Susmel, P Mcbride. 1998. Effects of rumen undegradable protein and feed intake on nitrogen balance and milk protein production in dairy cows. J Dairy Sci 81, 784-793. 